\title{
Hemostatic Therapy for Intracerebral Hemorrhage
}

\author{
Xingxia Wang1, Jie Gong1, Ping Gư ${ }^{1}$, Zhibao Zhao², Qingwen Jin ${ }^{1}$ \\ ${ }^{1}$ Department of Neurology, the First Affiliated Hospital of Nanjing Medical University, Nanjing, China \\ ${ }^{2}$ Department of Internal Medicine, Yizheng People’s Hospital, Yizheng, China \\ Email: acang1219176@sina.com, vlei1791313@sina.com,vwo6059453@sina.com, \\ mpo7513579@sina.com, htu6235969@sina.com
}

How to cite this paper: Wang, X.X., Gong, J., Gu, P., Zhao, Z.B. and Jin, Q.W. (2017) Hemostatic Therapy for Intracerebral Hemorrhage. Open Journal of Modern Neurosurgery, 7, 121-128.

https://doi.org/10.4236/ojmn.2017.74013

Received: July 26, 2017

Accepted: September 4, 2017

Published: September 7, 2017

Copyright $\odot 2017$ by authors and Scientific Research Publishing Inc. This work is licensed under the Creative Commons Attribution International License (CC BY 4.0).

http://creativecommons.org/licenses/by/4.0/ (c) (i) Open Access

\begin{abstract}
Objective: To reduce the blood pressure and elevate intracranial pressure using nimodipine (Nimotop Intravenous (IV) infusion). Thus, intracerebral hemorrhage was controlled, and the purpose of hemostasis was achieved. Methods: Sixty-eight patients with intracerebral hemorrhage were divided into a treatment group $(n=51)$, and a control group $(n=35)$. Nimotop solution $(10 \mathrm{mg})$ was administered as a fast-flowing IV infusion in the treatment group, and $250 \mathrm{ml} 20 \%$ mannitol infusion was given to patients in the control group twice every day. Patients in both groups received treatment for seven days, and the blood pressure on the treatment day was measured. A brain Computed Tomography (CT) scan was performed as a reexamination within two weeks. Results: The blood pressure in the treatment group was decreased from $179 / 104$ to $151 / 91 \mathrm{mmHg}$, averagely, and in the control group was decreased from $181 / 108$ to $180 / 103 \mathrm{mmHg}$, averagely. The difference between these two groups was statistically significant $(P<0.01)$. Hematoma enlargement occurred in 20 patients $(53.3 \%)$ in the treatment group, and four patients in the control group (8.57\%). The difference between both groups was statistically significant $(P<0.01)$. There were eight deaths in the treatment group. Seven deaths were caused by cerebral hernia, and one was caused by complications. There was one death in the control group caused by lung infection and gastrointestinal bleeding. Conclusion: Nimodipine can dilate the arteries, reduce blood pressure, and elevate intracranial pressure, lowering pressure gradients across vessel wall which destroy the vessel wall. Also, nimodipine can prevent hemorrhage as well as recurrent hemorrhage, and can used as the first choice of rescue drug. What's more, dehydration drugs such as mannitol should not be used in the early stage of intracerebral hemorrhage in order to prevent hematoma enlargement.
\end{abstract}




\section{Keywords}

Nimodipine, Intracerebral Hemorrhage, Hypertension, Cranial Hypertension

\section{Introduction}

Nimodipine (Nimotop IV infusion) is widely used to treat cerebral vasospasm and cerebral infarction after subarachnoid hemorrhage [1] [2] [3] [4]. In recent years, there is an animal experiment report of intracerebral hemorrhage treatment using nimodipine at home and abroad [5], and there are reports of clinical studies at home [6] [7] [8]. However, there has been no report on intracerebral hemorrhage treatment using nimodipine as the drug of first choice. From June 1995 to the end of December 2004, more than 400 patients with hypertensive intracerebral hemorrhage were treated with nimodipine in our hospital. However, among these patients, 51 patients received nimodipine treatment immediately after the recent onset. In addition, a control study was conducted on the 51 patients and 35 patients without nimodipine treatment. The former group gained relatively satisfied treatment efficacy as reported below.

\section{Information and Methods}

\subsection{General Information}

Subjects in the study were all patients treated in the Emergency Department of our hospital who met the following criteria: 1) acute hypertensive intracerebral hemorrhage, 2) within 24 hours of the onset of symptoms, 3) consciousness without coma, 4) quantitative estimation of hematoma was performed, and location of hematoma was identified using CT scan. Patients who met at least one of the following criteria were excluded from the study: 1) a systolic blood pressure < 100 mmHg; 2) gastrointestinal bleeding; 3) obvious liver dysfunction; 4) coma. Subjects were randomly assigned to two groups. There were 51 patients (33 males and 18 females) aged 45 to 84 years, with a mean age of $64 \pm 11$ years old in the treatment group. There were 35 patients ( 26 males and 9 females) aged 36 to 79 years, with a mean age of $60 \pm 11$ years old in the control group.

\subsection{Methods}

In the Emergency Department, two groups underwent blood pressure measurement, physical examination and brain CT scans. Nimodipine $(10 \mathrm{mg})$ was added into $500 \mathrm{ml} \mathrm{10 \%} \mathrm{glucose} \mathrm{water,} \mathrm{and} \mathrm{was} \mathrm{administered} \mathrm{via} \mathrm{IV} \mathrm{infusion} \mathrm{over} 3$ to 10 hours in the patients in the treatment group. The infusion was performed 1 to

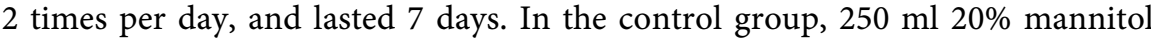
infusion was administrated every $8 \mathrm{~h}$ (q8h) or q12h every day. The infusion lasted for 7 days, and was finished within half an hour. In addition, an intra- 
muscular injection of reserpine (1 - $2 \mathrm{mg}$ ) was given to patients whose systolic blood pressure was more than $180 \mathrm{mmHg}$. Apart from the above differences in the two groups, patients in both groups were given $16 \mathrm{~g}$ 6-aminocaproic acid, nutritional agents for neurons and other drugs at the same time within 7 days. Mannitol or furosemide could be given for dehydration to comatose patients in the treatment group within 12 hours after the onset of symptoms in order to reduce intracranial pressure and ensure cerebral perfusion pressure. Blood pressure measurement was performed twice every day in both groups. Within two weeks, brain CT scans were performed as a reexamination in order to assess hematoma changes, and the time of onset, the first treatment and two CT scans was recorded.

\subsection{Criteria for Determining Efficacy}

First: Changes in blood pressure on the first day before and after treatment were used to determine the clinical efficacy.

Second: Changes in hematoma volumes detected by two brain CT scans were used to determine the changes in intracerebral hematoma volumes.

\subsection{Statistical Processing}

Changes in the blood pressure and hematoma volumes before and after treatment were examined using a $t$ or $t$ test, and hematoma location and expansion rates were examined using a chi-square test.

\section{Results}

Hematoma locations: there were 26 patients with putaminal hemorrhage, 12 with thalamic hemorrhage, 4 with lobar hemorrhage, 5 with brainstem hemorrhage, and 4 with cerebellar hemorrhage in the treatment group. There were 23 patients with putaminal hemorrhage, 6 with thalamic hemorrhage, 2 with brainstem hemorrhage, 3 with lobar hemorrhage, and 1 with cerebellar hemorrhage in the control group. The chi-square test performed on the hematoma locations in both groups showed a $P$ value larger than 0.05 , indicating that there were no significant differences.

The time from the onset to the first CT scan and from the first CT scan to the second CT scan in the two groups (Table 1).

Blood pressure changes on the first day of treatment in the two groups (Table 2).

Comparison of hematoma volumes in the two groups was detected by CT scan ( $\bar{x} \pm \mathrm{s} \mathrm{ml}$ ) (Table 3 ).

There were eight deaths in the control group, of which seven deaths were caused cerebral hernia, and of which one death was caused by hyperpyrexia and pulmonary infection on the day 9. There was one death in the treatment group. The patient died from pulmonary infection, hyperpyrexia, and gastrointestinal bleeding on the fifteenth day of the disease. 
Table 1. Comparison of the time from the onset to CT examination and from CT examination to CT reexamination between the two groups $(\bar{x} \pm \mathrm{s}, \mathrm{h})$.

\begin{tabular}{|c|c|c|c|c|}
\hline \multicolumn{2}{|c|}{$\begin{array}{l}\text { The time from the onset } \\
\text { to the first CT examination }\end{array}$} & \multirow{2}{*}{$\begin{array}{c}\text { Variances } \\
26.49\end{array}$} & \multirow{2}{*}{$\begin{array}{l}\text { The time from the first } \\
\text { to the second } \\
\text { CT examination } \\
147.79 \pm 86.38^{*}\end{array}$} & \multirow{2}{*}{$\begin{array}{r}\text { Variances } \\
7031.92\end{array}$} \\
\hline Treatment group $(n=51)$ & $4.37 \pm 5.83^{\star}$ & & & \\
\hline Control group $(n=35)$ & $3.09 \pm 3.34$ & 12.498 & $77.75 \pm 55.12$ & 2895.55 \\
\hline
\end{tabular}

The comparison of the time of two CT examinations between both groups showed ${ }^{\star} P>0.05$, indicating there were no significant differences.

Table 2. Blood pressure changes on the first day of treatment in the two groups $(\bar{X} \pm \mathrm{s}$ $\mathrm{mmHg}$ ).

\begin{tabular}{ccccc}
\hline & \multicolumn{2}{c}{ Before treatment } & \multicolumn{2}{c}{ After treatment } \\
\cline { 2 - 4 } & $\begin{array}{c}\text { Systolic blood } \\
\text { pressure }\end{array}$ & $\begin{array}{c}\text { Diastolic blood } \\
\text { pressure }\end{array}$ & $\begin{array}{c}\text { Systolic blood } \\
\text { pressure }\end{array}$ & $\begin{array}{c}\text { Diastolic blood } \\
\text { pressure }\end{array}$ \\
\hline Treatment group $(\mathrm{n}=51)$ & $179 \pm 25^{*}$ & $104 \pm 13.5^{*}$ & $159 \pm 16.9 \Delta$ & $89.6 \pm 11 \Delta$ \\
Control group $(\mathrm{n}=35)$ & $180 \pm 32.9$ & $103 \pm 14.2$ & $178 \pm 23.2$ & $107 \pm 17.41$ \\
\hline
\end{tabular}

Comparison of blood pressure between the two groups before treatment: ${ }^{\star} P>0.05$; after treatment: blood pressure $\Delta P<0.01$.

Table 3. Comparison of hematoma volumes in the two groups detected by CT scan $(\bar{x}$ $\pm \mathrm{s} \mathrm{ml}$ ).

\begin{tabular}{|c|c|c|c|c|c|c|}
\hline & & $\begin{array}{c}\text { Maximum } \\
\text { values }\end{array}$ & $\begin{array}{l}\text { Minimum } \\
\text { values }\end{array}$ & $\begin{array}{l}\text { Average } \\
\text { values }\end{array}$ & Variances & $\begin{array}{c}\text { Number of } \\
\text { cases whose } \\
\text { hematoma } \\
\text { volumes } \\
\text { increased }\end{array}$ \\
\hline $\begin{array}{l}\text { Treatment } \\
\text { group }\end{array}$ & $\begin{array}{l}\text { The } \\
\text { first time }\end{array}$ & 55 & 1 & $14.3 \pm 13.4^{\star}$ & 182 & \\
\hline$(\mathrm{n}=51)$ & $\begin{array}{c}\text { The } \\
\text { second time }\end{array}$ & 55 & 0 & $12.49 \pm 14.7 \Delta$ & 216.8 & $4 \boldsymbol{\Delta}$ \\
\hline $\begin{array}{l}\text { Control } \\
\text { group }\end{array}$ & $\begin{array}{l}\text { The } \\
\text { first time }\end{array}$ & 48 & 2 & $18.2 \pm 12.8$ & 163.8 & \\
\hline$(\mathrm{n}=30)$ & $\begin{array}{c}\text { The second } \\
\text { time }\end{array}$ & 88.5 & 2 & $28.43 \pm 20.91$ & 356.4 & 22 \\
\hline
\end{tabular}

Comparison of hematoma volumes between the two groups before treatment: ${ }^{\star} P>0.05$; after treatment: blood pressure $\Delta P<0.01$. Hematoma volumes in the control group significantly expanded. The comparison of the number of cases whose hem atoma volum es increased: $\mathbf{\Delta} P<0.01$.

\section{Discussion}

Among acute cerebrovascular diseases, hypertensive intracerebral hemorrhage is a major disease which causes high mortality. The main cause of death is whole-brain function impairment resulting from severe cranial hypertension due to hematoma hematoma. Therefore, the key to the treatment of intracerebral 
hemorrhage is how to stop hemorrhage. There is no clear understanding of the issue of hemostasis in many clinicians, and there are no specific hemostatic methods and measures. Currently, in the acute treatment of hemorrhagic stroke, most of our experts take measures to lower blood pressure and intracranial pressure, but the treatment concept is unclear. The new point of hemostasis proposed by us gives direction in the treatment of intracerebral hemorrhage.

In this paper, from June 1995 to December 2004, 86 patients were selected and divided into a treatment group and a control group. Cases diagnosed by the author were all in the treatment group. However, there was no double-blind randomized study. Chi-square tests performed on the sexes and hematoma locations in patients of both groups showed a $P$ value larger than 0.05 . A t or t' test was performed on ages, blood pressure, the time from the onset to the first CT scan, and hematoma volumes on the first CT scan, and showed a P value larger than 0.05 , indicating that patients in both groups were comparable. The changes in blood pressure in both groups after patients were treated with nimodipine (treatment group) and mannitol (control group) for one to seven days: blood pressure in the treatment group decreased from $179 / 104$ to $159 / 89 \mathrm{mmHg}$, and in the control group decreased from $180 / 103$ to $178 / 107 \mathrm{mmHg}$. Comparison between the two groups showed a $P$ values less than 0.01 , indicating that Nimotop IV infusion has an antihypertensive effect. CT reexamination found that hematoma enlargement occurred in 22 patients out of 35 patients $(62.8 \%)$ in the control group. In addition, there was one patient with multifocal hemorrhages. In contrast, there were only four patients with hematoma enlargement (accounting for $7.8 \%$, only two patients with obvious hematoma enlargement, and the remaining two patients with hematoma growth of 1 to $2 \mathrm{ml}$ ) in the treatment group. Comparison of hematoma volumes after treatment between the two groups was statistically significant $(P<0.01)$, indicating that Nimotop IV infusion can prevent hematoma enlargement, and has an antihypertensive effect on intracerebral hemorrhage. Among 24 patients with hematoma enlargement, hematoma enlargement occurred in $73 \%(19 / 26)$ within 3 hours with the maximum increase of up to $41.5 \mathrm{ml}$.

A study reported that hematoma continued to occur after up to 1 week or more [9]. In this paper, there was one patient in whom hematoma continued to increase 23 hours after onset, indicating that when blood pressure was not effectively lowered in the early stage of hypertensive intracerebral hemorrhage, intracerebral hemorrhage still occurred and last for a certain period of time. Hemorrhage volumes had an obvious relationship with blood pressure in the early stage of intracerebral hemorrhage in both groups after treatment. Such a low hematoma incidence and a small growth of hematoma in the treatment group might be results of changing blood pressure and adjusting intracranial pressure. That is, nimodipine, a calcium channel blocker, hinders excitationcontraction coupling in vascular smooth muscle, and dilates blood vessels. Systemic vascular dilatation lowers blood pressure and dilates intracranial blood vessels, increasing vascular bed and intracranial pressure. Such a decreased 
blood pressure and an increased intracranial pressure lowering pressure gradients across vessel wall which destroy the vessel wall, and reduce blood outflow rates so that the purpose of preventing hemorrhage is achieved and recurrent hemorrhage might be prevented in the late stage. Nimodipine improves the blood supply of hematoma peripheral nerve tissues through the expansion of cerebral blood vessels, and the lipid solubility of nimodipine allows it to pass through the blood-brain barrier and protect the neural function, especially the function of hematoma peripheral nerve tissues by preventing calcium overload in neurons. In theory, hemorrhage should be stopped immediately after hypertensive intracerebral hemorrhage is treated with infusion of nimodipine. There were four patients with hematoma enlargement in the treatment group. There may be a measurement error (less than $1 \mathrm{ml}$ ). Or hematoma expansion could be explained by the ongoing hemorrhage during the first CT examination and that there was a time interval between the CT examination and medication administration. In the control group, the early application of mannitol, reduced intracranial pressure, improved cerebral perfusion pressure on the surface [10], and prevented the formation of cerebral hernia. However, in fact, cerebral perfusion pressure differences were increased, and pressure gradients across vessel wall which destroy the vessel wall were increased. Blood more easily flowed out from the blood vessels, hematoma expanded, and intracranial pressure elevated. Cerebral hernia could easily form, and led to death, commonly causing progressive hemorrhagic strokes in clinical practice. In the eight deaths in the control group, seven were caused by cerebral hernia with hematoma volumes of more than 10 $\mathrm{ml}$. The occurrence of significant cranial hypertension resulted in fatal cerebral hernia. There was one death caused by lung infection, hyperpyrexia and gastrointestinal bleeding. There were significant differences in mortality rates between both groups $(P<0.01)$.

Now we are going to have a look at the causes of intracerebral hemorrhage.

Hypertensive intracerebral hemorrhage is due to long-term excessive vascular contraction leading to double nutrition disorders in brain small arterial and vascular smooth muscle, and microaneurysms. When the patient is in an agitated state, blood pressure further increased causing the rupture of microaneurysm. Blood flows out of the blood vessels, and intracerebral hemorrhage is formed [11] [12]. The hematoma volume is related to the following factors: 1) the size of the rupture of the aneurysm wall; 2) the diameter of the vessel with the aneurysm; 3) the distance from the heart to vessels with a certain diameter; 4) the blood pressure at that time, especially the systolic blood pressure; 5) the brain tissue pressure and intracranial pressure outside hematoma; 6) coagulation function. Among many relevant factors, there are several factors that we cannot change in the short term, such as the size of the rupture, the size of the aneurysm, the diameter of the vessel, and the distance from the heart to the rupture. Blood pressure, intracranial pressure and coagulation function can be effectively and artificially controlled. Blood pressure is easier to be controlled than intracranial pressure. There was no consensus on the issue to what extent blood 
pressure and intracranial pressure should be controlled. We propose that blood pressure should be lowered to stop hemorrhage. As long as the amount of blood supply in the brain tissue meet basic survival needs, blood pressure will be quickly lowered in order to stop hemorrhage. When blood does not flow, coagulation is easier to happen. In recent years, some scholars treated intracerebral hemorrhage with activated factor VII, and gained attention. We believe that it cannot have a good therapeutic effect, because intracerebral hemorrhage is not coagulation dysfunction. Brain tissue pressure outside hematoma is more special compared to subarachnoid space pressure. We can control transmembrane pressure gradients at the rupture of aneurysm by lowering blood pressure, especially systolic blood pressure, and increasing intracranial pressure, especially tissue pressure outside hematoma, so that blood cannon flow out of the rupture. This is basic principle of hemostasis by lowering blood pressure. Blood which stops flowing is prone to coagulation after coagulation factors are activated, and a vascular wall which can effectively resist some intravascular pressure forms. After a certain period of time, the damaged aneurysm wall or small arterial wall is repaired. Because the blood pressure is higher than the intracranial pressure, the newly formed hematoma oppresses the surrounding brain tissue, and produces brain tissue displacement, making the surrounding brain tissue capillaries and micro-venous lumina closed. Hypoxia and ischemia in the brain are caused by blocked venous return [13], resulting in neurological disorders in hematoma peripheral tissues, i.e. brain localizing psychic symptom.

\section{Conclusion}

In the early stage of hypertensive intracerebral hemorrhage, the first choice is treatment with nimodipine, which can immediately lower blood pressure and stop hemorrhage. This is a new method of hemostasis, and is efficacious especially for patients whose onsets are within 3 hours. In the early stage of intracerebral hemorrhage, mannitol and other dehydration drugs which reduce the intracranial pressure should not be used to avoid hematoma enlargement and exacerbation of the disease.

\section{References}

[1] Ma, Q.L. (1996) Effects of Nimodipine on Free Radicals in Cerebral Infarction and Subarachnoid Hemorrhage. Foreign Medical Sciences Section of Cerebrovascular Diseases, 4, 134.

[2] Harders, A., Kakarieka, A. and Braakman, R. (1996) Traumatic Subarachnoid Hemorrhage and Its Treatment with Nimodipine. German tSAH Study Group. Journal of Neurosurgery, 85, 82. https://doi.org/10.3171/jns.1996.85.1.0082

[3] Rousseaux, P., Gomis, P., Bazin, A., et al. (1993) Comparison of 2 Consecutive Series of Aneurismal Subarachnoid Hemorrhage with or without Nimodipine and Study of the Temperature Curve. Neurochirurgie, 39, 157.

[4] Hua, Y.S. (1995) Advances in the Study of Spontaneous Intracerebral Hemorrhage. Foreign Medical Sciences Section of Cerebrovascular, 3, 307.

[5] Li, G.Q. and Dong, W.W. (1988) A Preliminary Report on the Effect of Nimodipine 
on Ischemic Area and MPO Activity around Intracerebral Hemorrhage in Rats. Journal of Apoplexy and Nervous Diseases, 25, 58-59.

[6] Wang, X.X., Li, H.J. and Chen, W.X. (1998) A Preliminary Clinical Report on the Treatment of Hypertensive Intracerebral Hemorrhage with Nimotop. Jiangsu Medical Journal, 24, 819.

[7] Tai, L.W., Zhang, X.J. and Xue, X.P. (1998) A Prospective Clinical Study of Treatment of Edema around Intracerebral Hemorrhage with Nimotop. Journal of Apoplexy and Nervous Diseases, 15, 369.

[8] Guo, F.Q., Yang, Y.S. and Song, W.Z. (2000) A Preliminary Report on the Effect of Calcium Antagonists on Local Cerebral Blood Flow in Hypertensive Intracerebral Hemorrhage and Clinical Changes. Journal of Brain and Nervous Diseases, 8, 129-131.

[9] Kazui, S., Naritomi, H., Yamamto, H., et al. (1996) Enlargment of Spontaneous Intracerebral Hemorrhage. Incidence and Time Course. Stroke, 27, 1783. https://doi.org/10.1161/01.STR.27.10.1783

[10] Zhang, Y., Jiang, M.H. and Liu, D.S. (1978) A Study on in Electroencephalography and Histopathological Changes in Experimental Intracerebral Hemorrhage at Different Stages. Journal of Apoplexy and Nervous Diseases, 4, 138.

[11] Takebayashi, S. and Kaneko, M. (1983) Electron Microscopic Sttudies of Ruptured Arteries in Hypertensive Intracerebral Hemorrhage. Stroke, 14, 28. https://doi.org/10.1161/01.STR.14.1.28

[12] Wang, X.X. and Wang, Y. (2000) Discussion on the Pathogenesis of Hypertensive Arteriosclerotic Cerebral Hemorrhage. Hainan Medical Journal, 11, 4-6.

[13] Chu, X.F., Qu, S.B. and Feng, S. (1988) A Study on Continuous Bleeding after Hypertensive Intracerebral Hemorrhage. Journal of Apoplexy and Nervous Diseases, $15,25-27$. 